\title{
Analysis and Implement of Broadcast Program Monitoring Data
}

\author{
Jin Bao Song ${ }^{1, a}$, Lun Lun Huang ${ }^{1}$ \\ ${ }^{1}$ Information Engineering School, Communication University of China, Beijing, China
}

\begin{abstract}
With the rapid development of the radio and TV industry and the implementation of INT (the integration of telecommunications networks, cable TV networks and the Internet), the contents of programs and advertisements is showing massive, live and interactive trends. In order to meet the security of radio and television, the broadcast of information have to be controlled and administered. In order to master the latest information of public opinion trends through radio and television network, it is necessary research the specific industry applications of broadcast program monitoring. In this paper, the importance of broadcast monitoring in public opinion analysis is firstly analysed. The monitoring radio and television programs broadcast system architecture is proposed combining with the practice, focusing on the technical requirements and implementation process of program broadcast, advertisement broadcast and TV station broadcast monitoring. The more efficient information is generated through statistical analysis, which provides data analysis for radio and television public opinion analysis.
\end{abstract}

\section{Introduction}

The program analysis of broadcasting and television public opinions is the analysis of public opinion in essence. Public opinion is people's social and political attitudes on the social management surrounding the occurrence, development and change of the intermediary social events in the certain social space. It is the sum of the performance of beliefs, attitudes, opinions and emotions and so on expressed by the more public about the various phenomena in the society[1]. Public opinions form rapidly and have the huge influence to the society. Not only Party and government cadres at all levels need to pay close attention to public opinions, but also the all sectors of society need pay great attention to public opinions[2]. In general, the broadcast television public opinion analysis is an important part of radio and television industry.

Newspapers, broadcasting, television, network is the main channel reflects the social public opinion. Compared to newspapers and network, it determines that broadcasting and television has the characteristics of public opinion:

1) timeliness; through the cable and satellite transmission, they can quickly cover nationwide.

2) authority; It reports and publicizes the policies of the government.

3) popularity; Broadcasting's coverage rate is $98 \%$.Television's coverage rate is $92 \%$. They are the most common direct access to information sources for people[3].

Along with the development of broadcasting and television, broadcasting television public opinion analysis

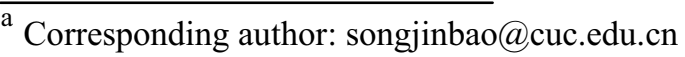

is taken seriously more and more, and become an important and hot research topic[4]. As the mainstream, the authoritative media, broadcasting and television public opinion analysis hasn't been researched on due to the restrict of one-way transmission. Lack of the situation analysis and statistics of broadcasting and television, it restricts the further development of broadcasting and TV industry[5].

In order to make the public opinion analysis system can be more complete and the concluded analysis data can be more standard, the national radio and television broadcasting must be monitored[6]. In order to improve the quality and level of radio and television broadcast and transmission, ensure the safety of radio and television broadcast and transmission quality and prevent the radio and television fault broadcasting, bad broadcasting even off the air, we must strictly monitor the radio and television signal[7]. We should not only investigate users viewing behaviour, but also monitor the broadcast content of radio and TV station and cable TV in every district in cities in order to understand the national radio and television broadcasting[8].

The study of this topic in the information society and the media, under the background of the accurate diagnoses in national broadcasting and television, promotes the influence and approval of radio and television broadcasting a healthy and orderly, harmonious development.

\section{The monitoring radio and television programs broadcast system architecture}




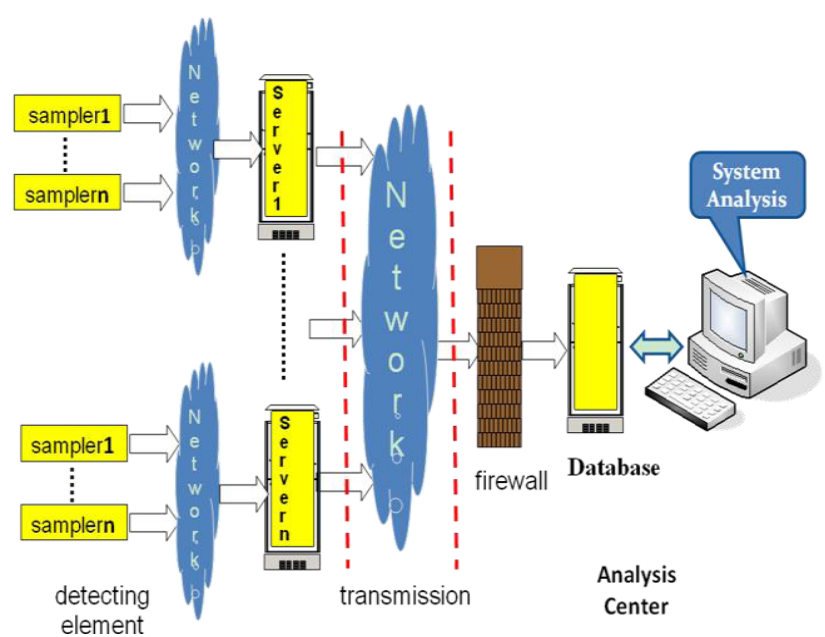

Figure 1. The monitoring radio and television programs broadcast system architecture

The show program source is gained from detecting cities. There are two types of program, type I superimposed by watermarking, type II without any watermarking. The pictures of each shown program are sampled from cable television network using frame samplers. Then the data is stored in the disk, encrypted and transmitted back to analysis center using the Internet at night when network isn't busy. All the information enters the data storage structure through the Internet according to frame dispatching mechanism in the analysis center. For type I, watermark is decoded. For type II, it is treated with image matching retrieval. The formation of the actual radio and television broadcast programs data and audience rating data is produced by the two ways. Then all the information data entries processing and management system. In management system, through radio and television broadcast content analysis software will do data mining and statistical analysis of various content[3].

The concrete modules of the monitoring radio and television programs broadcast system are as follows:

- frame sampler module

- frame sampler dispatching module

- television content watermark superimposition and recognition module

- image matching and recognition module

- program background information data module

- storage structure, database module

- broadcasting and television public opinion analysis software modules

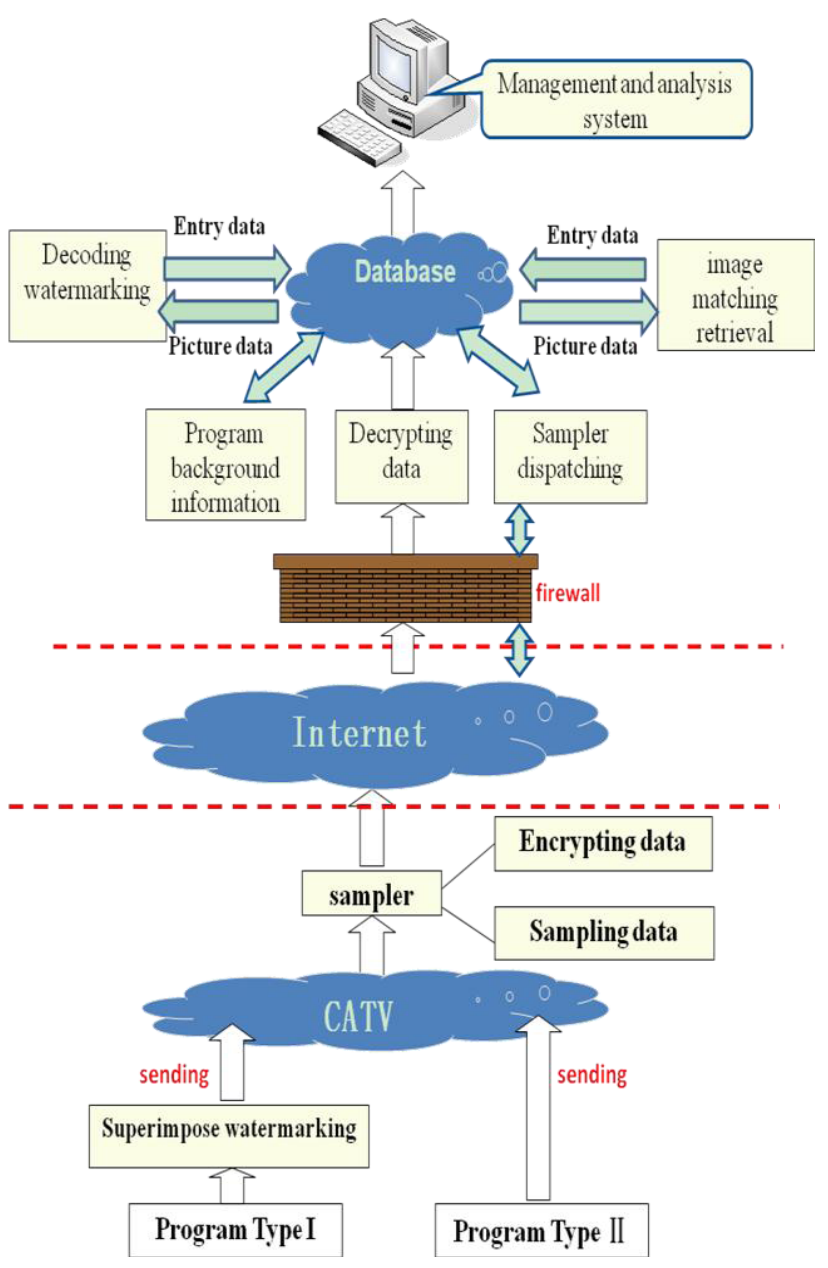

Figure 2. The concrete modules of the monitoring radio and television programs broadcast system

\section{Program monitoring analysis}

As is known to all, now broadcasting and making program are divided. The program production company makes program. Then, the program is broadcast by television station. The company of program production will receive payment from TV station. But a lot of television stations, especially at county level, use a way of recorded broadcast from province station program or CCTV and broadcast within the scope of the county in reality. A lot of royalties have been seriously lost by company of program production. Therefore program monitoring analysis is being researched by us. The above functions will be achieved in program monitoring analysis module. It is necessary to filter data in the database, including city, broadcasting television station, broadcasting time, broadcasting duration, program categories, keywords of program, program production company, broadcasting date. Graphics drawing pattern is set when statistical graphics are drawn after filtering data, which makes the final result of the statistical analysis more practical.

\subsection{Statistical analysis based on program production company}


Many of the high audience ratings programs broadcast by television stations are purchased from some high level program production companies. The audience ratings of program are the important indicator of television stations. So more and more television stations begin to pay more and more attention to program production companies of high level. At the same time, along with the increasingly competition among the program production companies, it is particularly important to show the ranking information of the production companies generated by the statistics of broadcast data. The ranking information of the program production company can be generated by the program monitoring analysis system through filtering broadcast data. The following example is the ranking information of program production companies in the statistical analysis of CCTV 1 channel, as shown in figure 3 . It can be seen through the graphic that China TV drama production center has established nearly a quarter of the broadcast television program in the program production companies in China central television (CCTV) - 1 .

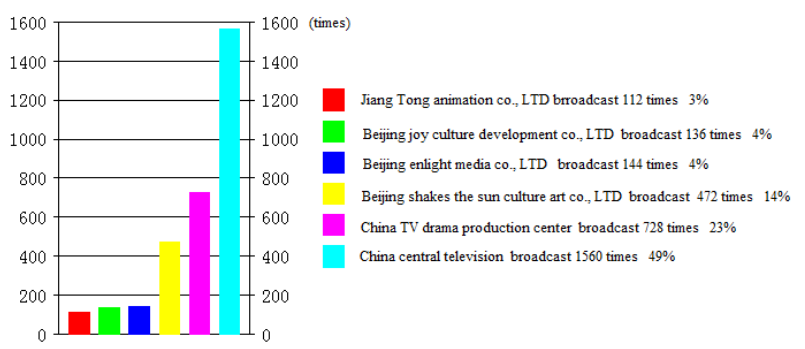

Figure 3. The ranking information of program production companies broadcast on CCTV-1

The broadcast data can also be firstly selected depending on the type of programs. And then the ranking information is carried out in accordance with the programme production company list. So you can know the strength of some program production company in the field of the special program production. For instance, statistical analysis to the ranking information of program production companies in cultural entertainment programs broadcast on CCTV-1 and CCTV-4 channel as shown in figure 4.

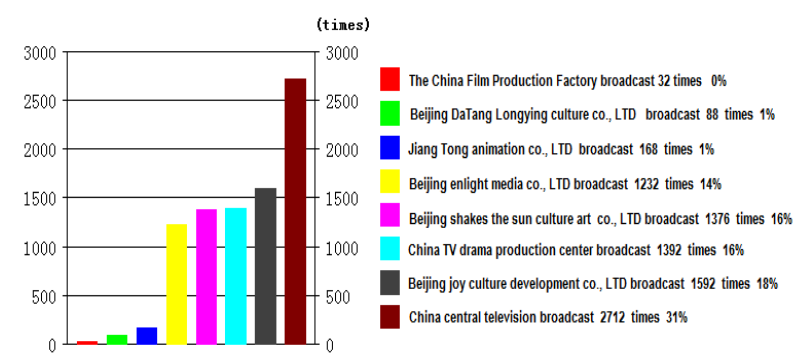

Figure 4. The ranking information of program production companies in cultural entertainment programs broadcast on CCTV-1 and CCTV-4

Through the above statistical analysis, the purpose is to serve TV station and the company of program production. For television station, through the list statistics, one can choose the power program production companies for their production program. Besides, the station chooses people loved program in order to improve its audience rating. For company, it can know its rankings in the companies of program production and also can learn from this list of different production department of program company performance. The department with poor performance should be adjusted or eliminated. It provides the company decision-maker favourable adjustment accordance.

\subsection{Statistical analysis based on program type}

CCTV and the provincial satellite television stations establish a variety of non-integrated channels, such as economic channels, entertainment channels, news channels. Some satellite TV channels don't achieve the result of professional channel due to economic interests. For instance, in order to increase ratings and advertising revenue, the science and technology education programs are few in the education channel in broadcasting every day. These phenomena show that it is necessary to supervise the professional channels. At the same time, the state administration of radio, film and television also has corresponding measures with the establishment of these special channels, such as assuming that the proportion of economic programs in all broadcasting programs should not be less than $30 \%$ in the economic channels. So this analysis module can provide analytical data for government regulators. For example, the statistical analysis of the proportion of each type of program shown in CCTV-3 channel, as shown in figure 5. Through the figure we can see very clearly that among all programs broadcast by CCTV-3, cultural entertainment programs together with music programs common occupy nearly $73 \%$ proportion, which belongs to the normal range of broadcasting.

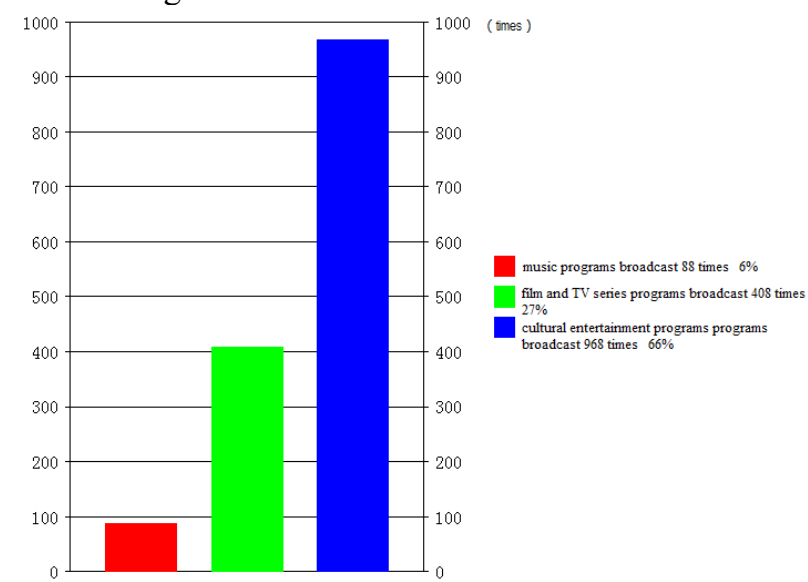

Figure 5. The statistical analysis of all kinds of programs shown in CCTV-3 channel

\section{Advertisement monitoring analysis}

The service object of advertisement monitoring analysis is the advertisement owner and the advertisement company. We know that advertisement owner that are mainly the manufacturers entrust the advertisement company to make advertisement. The advertisement will 
be shown on television. The ad-rate depends on five factors:

(1) the broadcast channels. BTV's ad-rate and CCTV's ad-rate are obviously discriminating. Different TV ad-rate is determined by the TV audience rating.

(2) the advertisement's broadcasting time. Prime-time ad-rate and non prime-time ad-rate are a great difference.

(3) the broadcasting duration. 9 seconds ad-rate and 15 seconds ad-rate are different.

(4) the advertisement's broadcasting times. Three times advertisement and one time advertisement have different ad-rate.

(5) the broadcast order. This is the most neglected advertisement monitoring analysis of factors. For example, when television ad time begins, expenses of the first ad and of the third ad will also be different. The audience may change to other channels when the third advertisement begins. The similar product advertising affects advertisement effect each other if similar advertisements broadcast one by one. So advertisements sequence also need to include into public opinion analysis[3].

\subsection{Statistical analysis based on the advertisement company}

An important index that advertisement owner chooses the advertisement company is to check the occupancy of the advertisement market. By means of the statistical list of advertisement companies of advertising information broadcast in a channel or an area, the advertisement company's market share can be analysed within a specified channel or regional. For example, through the statistical analysis of advertisement broadcast on CCTV2 , advertisement companies share can be carried out in all entry broadcasting advertisement information, as shown in figure 6 .

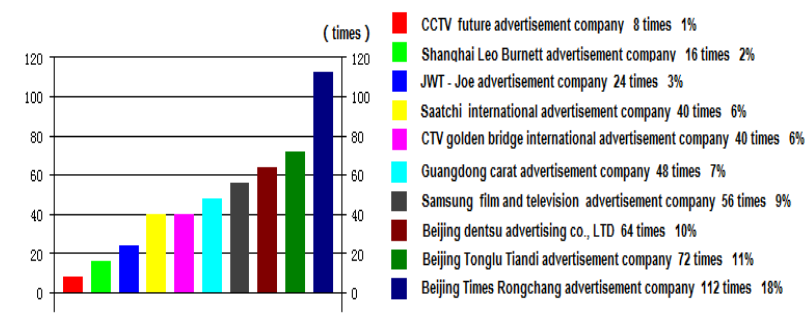

Figure 6. The statistical analysis of advertisement companies share shown on CCTV-2

In addition, the advertisement monitoring analysis also includes various ranking list statistics and comparison of statistics of similar products advertisement. Purpose is to serve the advertisement owner and the advertisement company.

For the advertisement owners, through the list statistics and comparative statistics of similar products, one can choose the power advertisement company to make advertisement. The advertisement owners also can understand their products in the same products in position.
The company can understand relationship of the sales of its products in the different regions and its advertisement in different areas. Then, the company can adjust its advertisement strategy.

For the advertisement company, it can know its rankings in advertisement and also can learn from this list of different production department of the advertisement company performance. The department with poor performance should be adjusted or eliminated. It provides the company decision-maker favourable adjustment accordance.

\subsection{Statistical analysis based on the advertisement broadcasting}

Advertisement owners generally advertise on television for profit, which makes the enterprise occupy a broader market, sell production and take advantage with the competitors of similar products. The competition doesn't just exist in the market. There is competition in the advertising. The advertisement owners can get competitors' advertising information in order to make the next step of advertising strategy.

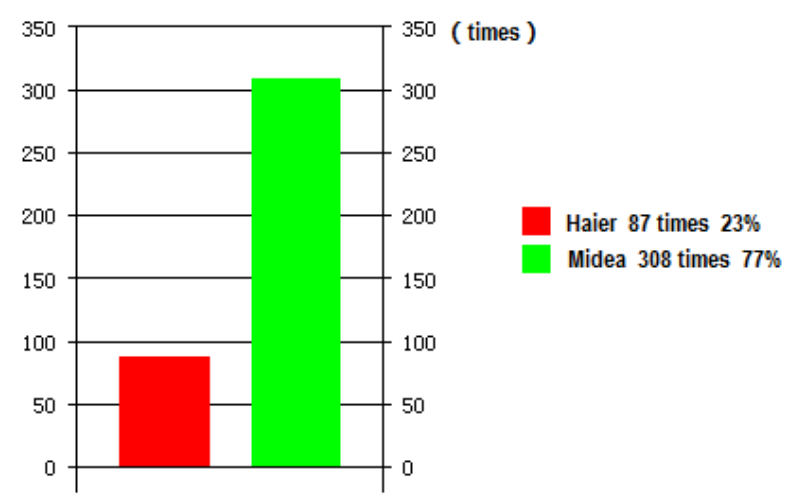

Figure 7. The contrast situation of Haier and Midea airconditioning advertising

Advertising is also pay attention to broadcasting time. No matter how good the advertisement is produced and how many the advertisements are delivered, it will be nothing if you can't arrange the broadcasting time well. It also cannot achieve the desired effect. So the advertisement owner must do market research ahead when advertising and analyse the effect of time factors on the advertisement effect. At the same time, the advertisement owner can also get statistics data of the successful advertising companies in the industry for reference. 


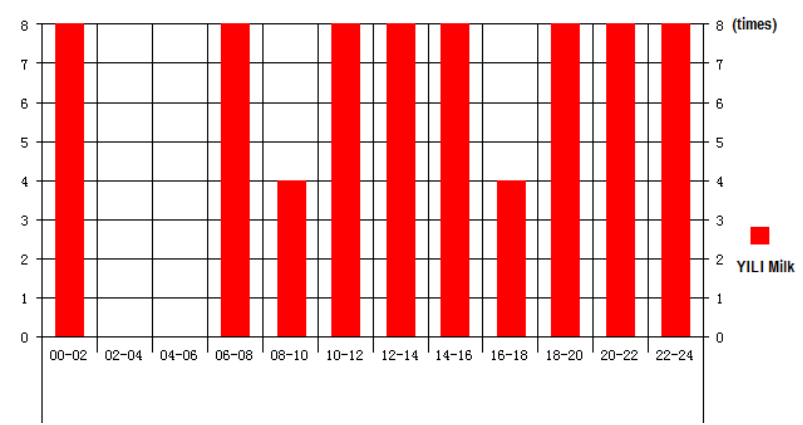

Figure 8. The broadcasting situation of YILI milk advertisement for one day

\section{Summary}

The broadcast program monitoring analysis system presents multiple analysis methods and realizes the combination of the monitoring and analysis in the exploration. The statistical analysis services are provided for television stations, program production companies, advertising companies, advertising owners, government, and so on. The television broadcast information is made good use of. The research and application of this topic have wide development prospects.

\section{References}

1. L.H. Wang. Public Opinion Overview: theory, method and realistic hot . Tianjin: tianjin academy of social science press, 2003.

2. Xu Xin, Zhang Zhicheng. Research on Application and analysis of Internet Mediated Public Sentiment[J]. Information Science, No 8,2008,11941201.

3. Song Jinbao, Chai Jianping. An Analysis System of Broadcasting and Television Public Opinions[J]. Proceedings-International Conference on Management and Service Science(MASS2009),2009,9,923-927.

4. K.L.ZHANG. National Decision: mechanism and public opinion. Tianjin: tianjin academy of social science press, 2004.

5. Qian Aibing. A Model for Analyzing Public Opinion Under the Web and Its Implementation[J].Xiandai Tushu Qingbao Jishu, No 4,2008.

6. Y.S.CHEN. Colony Accidents and Public Opinion.Tianjin: tianjin academy of social science press, 2005.

7. J.BE. Try to Spread the Era of High Technology.journal of early experiments in 2006, News Journalists, (4) : 29-31.

8. G.LIU. in public opinion. The Function of Media Collection and Analysis of the Mechanism.Journal of Chinese reporters, 2005, (9) : 14-16. 